\title{
Experimental measure of impact in temporary handrails
}

\author{
J. C. Pomares ${ }^{1}$, B. Ferrer ${ }^{1}$, D. Más ${ }^{2}$, C. Lozano ${ }^{3}$, S. Bresó ${ }^{3}$ \\ \& R. Irles ${ }^{1}$ \\ ${ }^{I}$ Civil Engineering Department, Alicante University, Spain \\ ${ }^{2}$ Optical, Pharmacology and Anatomy Department, \\ Alicante University, Spain \\ ${ }^{3}$ AIDICO Laboratory, Valencia, Spain
}

\begin{abstract}
In recent years, previous work with numerical models of impact generated by a fall on edge protection systems (EPS), class C according to EN 13374, showed that current requirements for this system could be inadequate or dangerous for the integrity of injured people, leading to excessive impact factors. Special difficulties arise when the injured fall directly against the EPS supports.

To confirm the results of numerical models, two series of experiments were developed using real size samples built with a steel frame and a safety net or other stop surfaces. The paper describes these experiments carried out according to EN 13374 and using a new design of supports with a curved slope to avoid direct impact against them. Data was recorded with a triaxial accelerometer and a high velocity camera.

The first series, with a standard safety net, showed a very good behaviour, leading to acceptable impact factors and no direct impact against the frame. The second series was conducted on a reinforced frame and substituting the net by a thin steel bar grid, to reduce the deflection up to the minimum required in EN 13374.

The results confirmed the numerical predictions and show that current requirements lead to excessive impact factors that can seriously injure the falling person, suggesting a revision of the European Norm.

Keywords: handrails, fall, impact, impact factor, high velocity camera, EN13374, safety, net.
\end{abstract}




\section{Introduction}

Recent research regarding impacts against a type $\mathrm{C}$ provisory edge protection system (for slopped working surfaces) and other security devices has been made with a numerical model based on finite elements [1-4]. Requirements for this protection system are established by code EN 13374 [5] and include minimum values for some geometrical and mechanical variables. Among them there are the height of protection $(\geq 1 \mathrm{~m})$ from working surface, their inclination and the minimum deflection of the system $(200 \mathrm{~mm})$ when a $75 \mathrm{~kg}$ ballast falls down against it, in a test required by the code $[6,7]$. All these variables are directly implied with the safety of a person falling on the surface. These variables must guarantee the retention of potential victim with forces on their body low enough to not injure it severely.

Results of numerical models suggested that current minimum height and deflection of the protection required by code could be insufficient and dangerous. During the retention process the body could reach an elevation of approximately $1 \mathrm{~m}$ from the working surface, overpassing the protection or hitting the upper rigid part of the system with a vulnerable body part. On the other hand, for the current minimum deflection required to the system, numerical models showed excessive forces during the few hundreds of miliseconds that the retention lasts. These forces derive from decelerations suffered by the body until its velocity vanishes and are usually referred to by the named Impact Factor, which is the quotient between the maximum instantaneous acceleration and that of gravity.

As all these questions are relevant for the security, some experiments with real models conforming EN 13374 were carried out to confirm the predictions of numerical models, and some modifications are proposed to be included in a future revision of this code. The experiments will also be useful to calibrate the numerical models, if necessary, for future device design processes.

\section{Samples and experiments}

As a result of previous studies [8, 9], an original system was developed for class $\mathrm{C}$ protection provided with a steel frame with curved supports fastening a $2 \mathrm{~m}$ width safety net as arrest surface (figure 1). The midline geometry of these

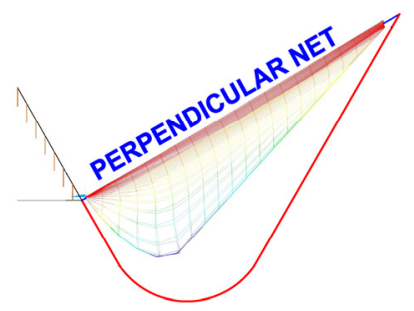

ERGONOMIC SUPPORT

Figure 1: Original system of the ergonomic support. 
"ergonomic" supports was designed to avoid direct impacts when the ballast (as it was a person) falls down directly towards them, allowing deflection enough of the net to avoid major injuries on the person that falls. This is an unsolved question in current version of EN 13374.

Several samples or this kind of protection were made with a hollow steel section $\varnothing 48 \times 3 \mathrm{~mm}$ and two or three curved supports (figure 2).

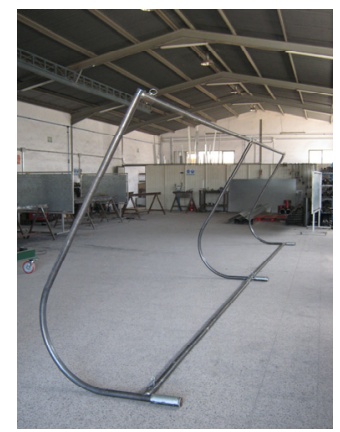

Figure 2: $\quad$ Ergonomic supports.

Two series of experiments were developed. The first was conducted to confirm several aspects predicted by numerical models, verifying:

-the ability of new design supports to avoid direct impacts, -the deflection of the net,

-the impact factor that the falling person suffers and

-the ballast elevation over the working surface during the retention.

Related to the last point, the numerical model predicted elevations near $1 \mathrm{~m}$ (minimum required) with possible direct impacts against the upper rigid part of protection and even overpassing it and falling down to void. This series consisted of two impacts against midspan of the net, with only two supports, and two impacts facing the central support of an assembly with three supports detached $4 \mathrm{~m}$ of each other.

The numerical models also predicted net deflections much greater than $200 \mathrm{~mm}$ (current required minimum by the code) with acceptable impact factors. Moreover, diminishing the deflection to the required minimum value leads to much higher and dangerous impact factors. Then, the second series of experiments focused on verifying and quantifying this point. So that, a reinforced frame was used with an assembly of three hollow steel tubes with section of $\boldsymbol{O}$ $48 \times 3 \mathrm{~mm}$ welded as central support (figure 3 ). The safety net was substituted by a ठ $5 \mathrm{~mm}$ steel wire grid of $150 \times 150 \mathrm{~mm}$. This series consisted of two impacts in the plane of central reinforced support.

In all experiments the ballast was provided with an accelerometer located at its axis (figure 4) and the entire retention process was recorded in a high speed camera (figure 5) at 512 frames per second. Experiments were developed in 


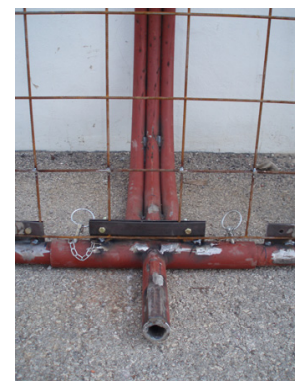

Figure 3: $\quad$ Reinforced support.
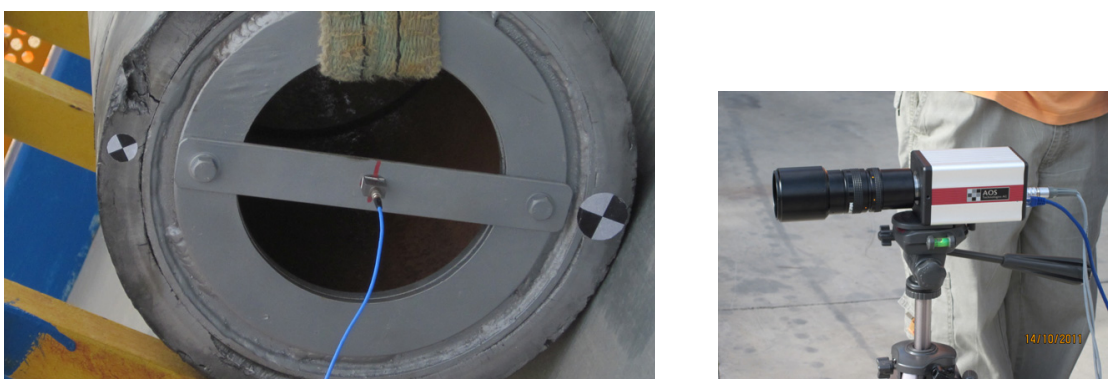

Figure 4: Accelerometer location. Figure 5: High speed camera.

AIDICO construction research institute (Valencia, Spain) and conducted according to requirements of EN 13374 for this protection system, that is to say, the $75 \mathrm{~kg}$ ballast of $1 \mathrm{~m}$ length falling along $5 \mathrm{~m}$ on a surface slopped $60^{\circ}$ from horizontal up to contact the protection system (figure 6). Accelerometer directly gives acceleration. Net deflections, ballast path and accelerations can also be obtained from postprocessing images from high speed camera [10].
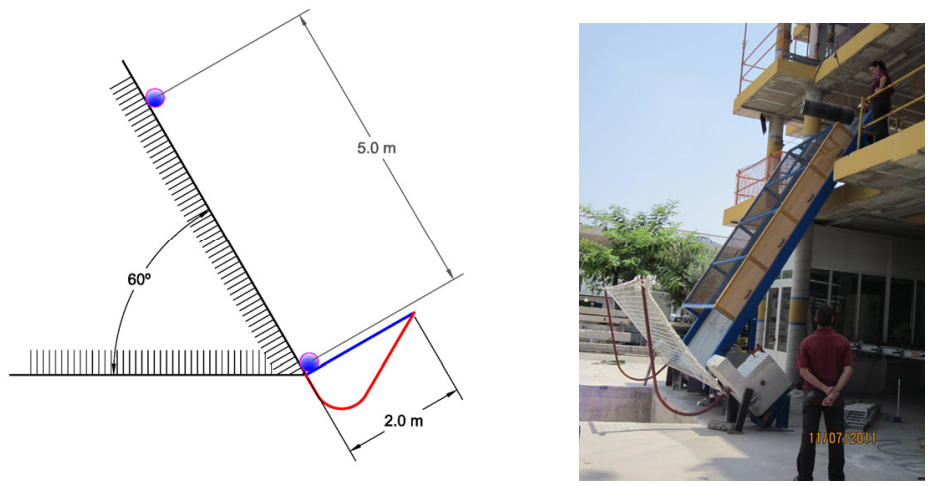

Figure 6: Requirements of EN 13374 for this protection system. 


\section{Results}

\subsection{First series of experiments}

Figure 7 shows the acceleration measured by the accelerometer for midspan impact corresponding to (a) the first impact and (b) the second one; figure 7 (c) shows the numerical model prediction.

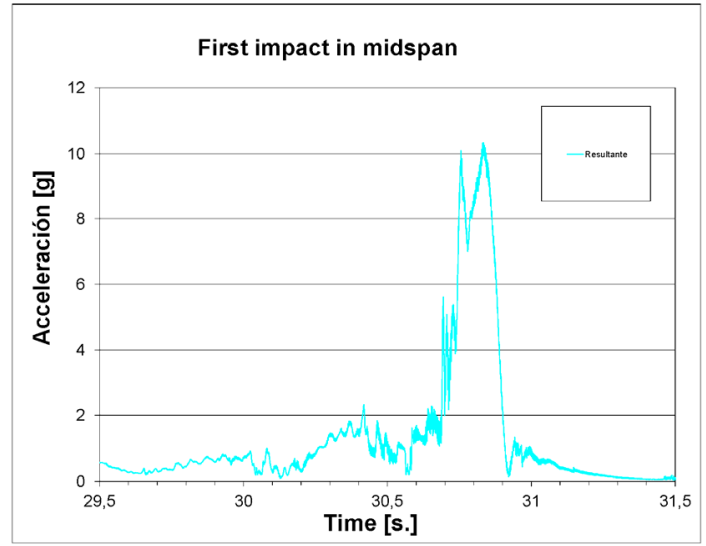

Figure 7 (a) Accelerometer record for $1^{\text {st }}$ impact at net midspan.

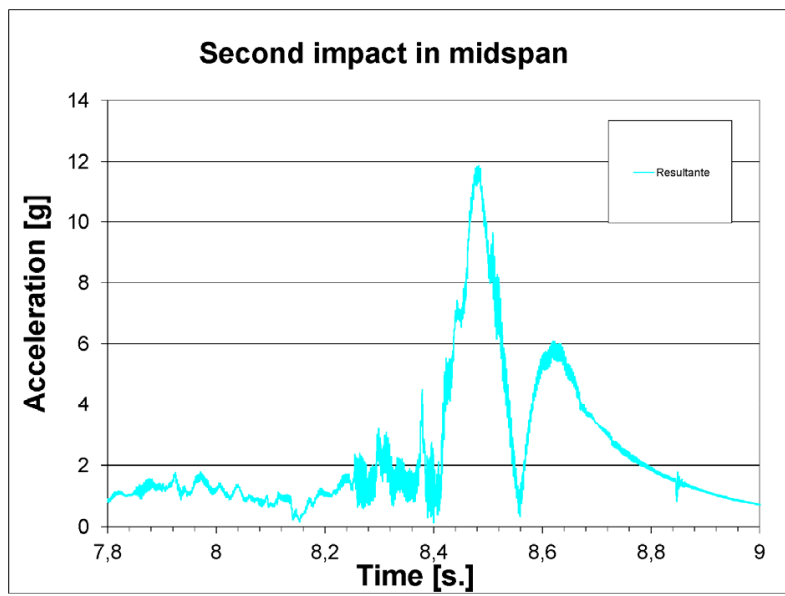

Figure 7 (b) Accelerometer record for $2^{\text {nd }}$ impact at net midspan. 


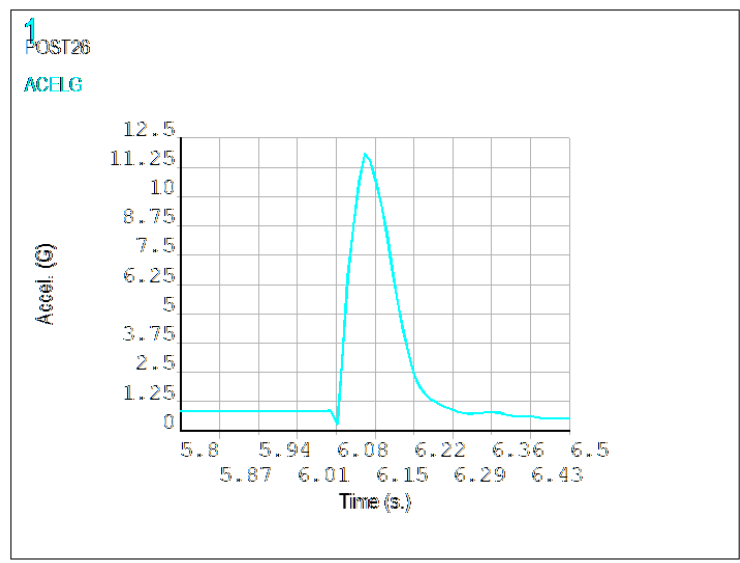

Figure 7 (c) Numerical prediction of acceleration for impact at net midspan.

Similarly, figure 8 shows the graphs corresponding to impact in the plane of central support. As it could be expected, from these results it can be seen that impacts in the plane of central support are more severe due to considerable plastic deflection of handrails in the case of midspan impacts. Experimental results agree well with numerical ones, although net stiffness in the model seems to be a few over estimated.

Images from high speed camera were processed with special techniques [10], including automatic shape (of cylindrical ballast) recognizing to obtain the ballast path. It is drawn for impact in plane of support in figure 9 (first impact).

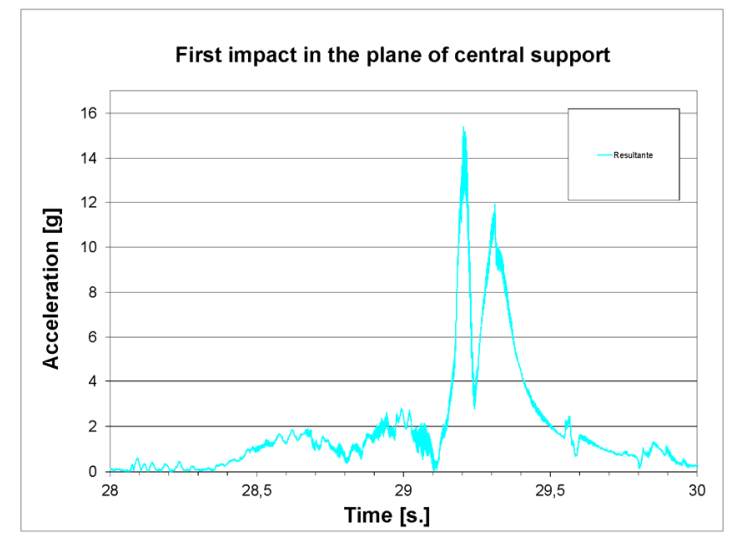

Figure 8 (a) Accelerometer record for $1^{\text {st }}$ impact in face of the net central support. 


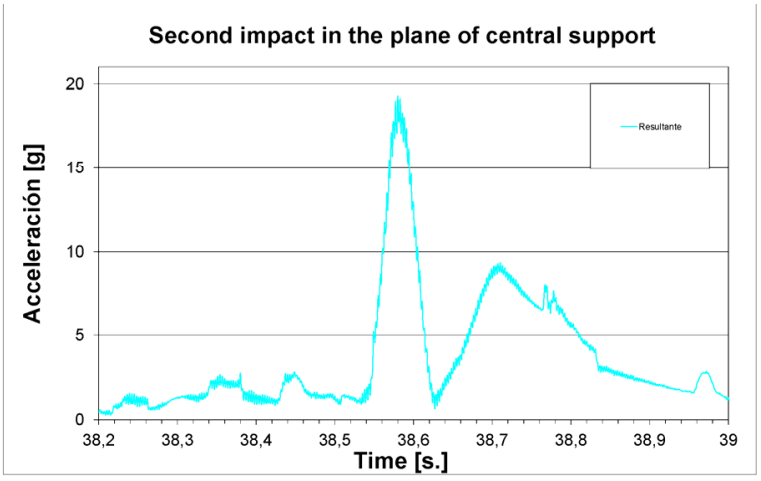

Figure 8 (b) Accelerometer record for $2^{\text {nd }}$ impact in face of the net central support.

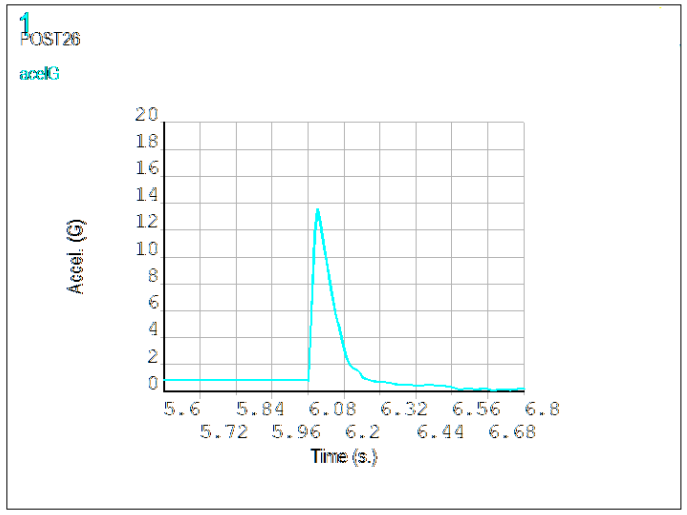

Figure 8 (c) Numerical prediction of acceleration for impact in face of the net central support.

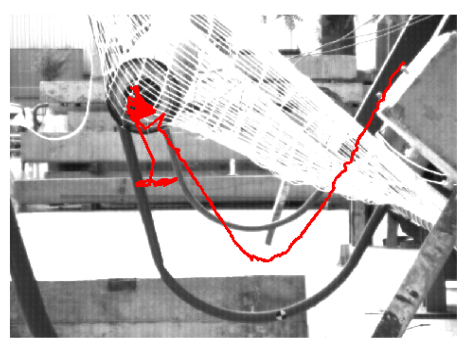

Figure 9 Cylindrical ballast path. 
These techniques also allowed us to obtain numerical temporal derivatives of ballast location, so the acceleration along time being adjusted by polynomial expressions of different degrees. Figure 10 shows acceleration history for impact in the plane of central support. In every case, all curves significantly coincide for maximum values, although it shows few miliseconds of difference in reaching it. The agreement with maximum values read by accelerometer is acceptable.

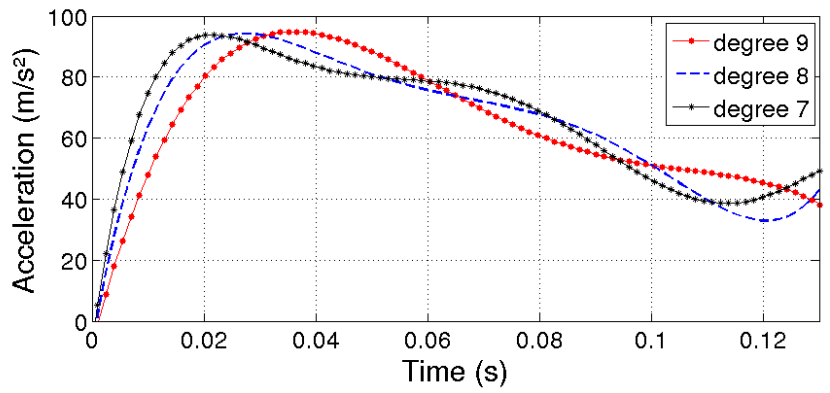

Figure 10 Acceleration history adjustments.

Table 1 summarizes the maximum deflection $\left(\mathrm{d}_{\max }\right)$, the ballast elevation $\left(e_{\max }\right)$ over working surface and the impact factor (I. F.) for this series of experiments.

Table 1: $\quad$ Maximum movements and I.F. for net prototypes.

\begin{tabular}{|c|c|c|c|}
\hline Impact & $\mathrm{d}_{\max }(\mathrm{m})$ & $\mathrm{e}_{\max }(\mathrm{m})$ & $\mathrm{I} . \mathrm{F}$. \\
\hline Net midspan 1 & 0,85 & 1,45 & 11,5 \\
\hline 2 & 0,80 & 1,50 & 12,0 \\
\hline In support plane 1 & 0,75 & 1,00 & 13,0 \\
\hline 2 & 0,65 & 0,83 & 16,0 \\
\hline
\end{tabular}

\subsection{Second series of experiments}

In the case of reinforced system, designed to reduce the maximum deflection to the minimum value required by EN $13374(200 \mathrm{~mm})$, figure 11 shows the acceleration read by the accelerometer, (a) for the first impact, (b) for the second one and (c) as predicted by numerical model. Experiment results agree well with numerical ones. 


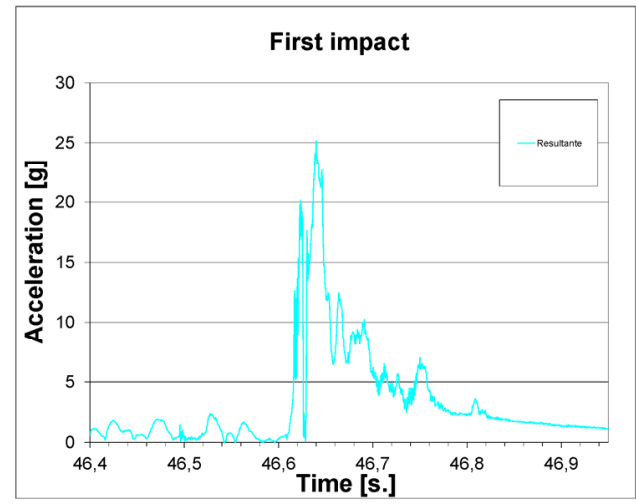

Figure 11 (a) Accelerometer record for $1^{\text {st }}$ impact against steel grid.

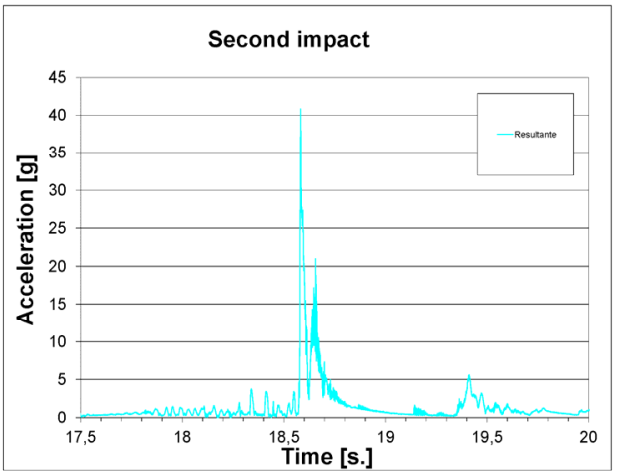

Figure 11 (b) Accelerometer record for $2^{\text {nd }}$ impact against steel grid.

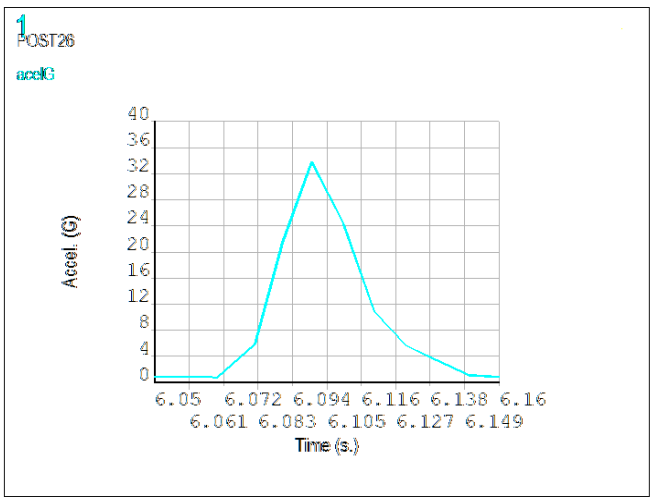

Figure 11 (c) Numerical prediction of acceleration for impact against steel grid. 
By means of the above mentioned image process techniques, figure 12 shows the ballast path for first impact. And figure 13 shows the polynomial adjustments for acceleration history.

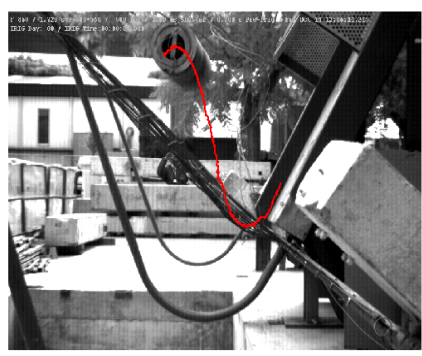

Figure 12 Cylindrical ballast path.

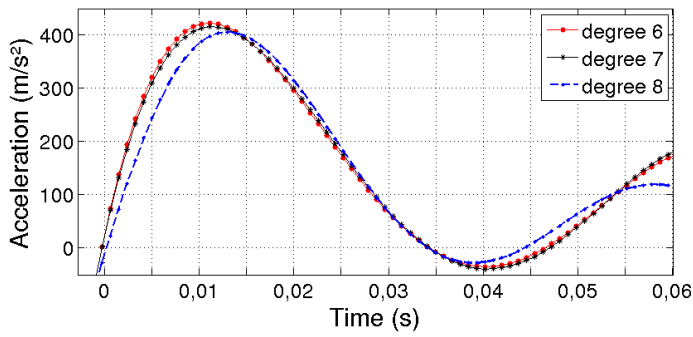

Figure 13 Acceleration history adjustments.

Table 2 summarizes the net maximum deflection, the ballast elevation over working surface and the impact factor for these experiments.

Table 2: $\quad$ Maximum movements and I.F. for steel grid prototypes.

\begin{tabular}{|c|c|c|c|}
\hline Impact & $\mathrm{d}_{\max }(\mathrm{m})$ & $\mathrm{e}_{\max }(\mathrm{m})$ & $\mathrm{I} . \mathrm{F}$. \\
\hline Net midspan 1 & 0,20 & 1,1 & 32,5 \\
\hline 2 & 0,17 & 1,4 & 40,0 \\
\hline
\end{tabular}

Maximum values from accelerometer and high speed camera agree well, with few differences, and confirm the prediction of numerical model in the sense that reducing the maximum deflection value to the minimum one currently required by EN 13374, it results in great impact factors against the injured, inadmissible for this security device $[11,12]$. These evidences suggest a revision of current values for minimum deflection and minimum protection height in normative requirements. 


\section{Conclusion}

Results of experiments carried out with real samples of provisional edge protection class C (EN 13374) agree well with previous results from numerical finite element models. Measurements of accelerometer and high speed camera show that:

1.-Current required minimum height of protection could be inadequate to arrest the injured people. The risk arises in hitting the upper rigid border of protection, or even in overpassing it (then falling down to void). So, in a future revision of EN 13374, an increment of this minimum height must be considered up to a 1.5$2.0 \mathrm{~m}$ value.

2.-With an ergonomic design of protection supports, the experiments show that direct impact against it can be avoided. So, in a future revision of the norm, minimum deflection requirement could be extended to overall protection system, including the support zones.

3.-Experiments with a class $\mathrm{C}$ protection system with a safety net carried out conforming to EN 13374 showed that a deflection near to $700-800 \mathrm{~mm}$ was developed when the accelerometer and high speed camera measured accelerations near to $10-12 \mathrm{~g}$, this values being reasonable.

4.-Experiments with a more rigid system reducing the deflection to the currently required minimum value $(200 \mathrm{~mm})$ revealed that acceleration reaches much higher values, near $40 \mathrm{~g}$, that could seriously injure the falling person. Then, in next code revision this minimum deflection must be increased to a very higher value, near to $700-800 \mathrm{~mm}$.

\section{Acknowledgement}

We acknowledge the support given by Metálicas López, whose factory supplied freely all samples for experiments, and the support given by AIDICO laboratory for carrying out the experiments above described with no charges.

\section{References}

[1] Irles, R., Maciá, A., Segovia, E., Saiz, J. "Vertical Security Nets. Theoretical and Experimental Results" III European Forum in Science, Security and Health, Oviedo (Spain), 1.998. (In Spanish).

[2] Irles Más, R, González Sánchez, A., Segovia Eulogio, E., Maciá Mateu, A. "Vertical Security Nets in Building Construction I". Informes de la Construcción, volume 53, No 477, 21-29, 2002.

[3] Segovia Eulogio, E.G., Doctoral thesis: Criteria for the design of fall arrest systems used in construction and subjected to impact. September 2004.

[4] Segovia Eulogio, E., Irles Más, R., González Sánchez, A., Maciá Mateu, A., Pomares Torres, J. C. "Vertical Security nets in building construction II". Informes de la Construcción, volume 59, n 505, 37-51, January-March 2007. 
[5] EN 13374:2004 Temporary Edge Protection Systems Product Specification, test methods. CEN (2004).

[6] UNE-EN 1263 Security Nets. Part 1: Security requisites, Test methods. AENOR, (2002).

[7] UNE-EN 1263 Security Nets. Part 2: Security requisites for installing Security nets. AENOR, (2004).

[8] Pomares, J.C, Segovia, E.G., Irles, R. Personal protection rails for strong impacts. $4^{\text {th }}$ Int. Confer. on Safety and Security Engineering, SAFE 2011. Antwerp (Belgium), July 2011.

[9] Pomares, J.C., Irles, R., Segovia, E. G., and Boixader, D. Personal protection guardrails for dynamic forces. Informes de la construcción (Accepted 2011).

[10] Ferrer, B., Pomares, J.C., Irles, R., Espinosa, J, Más, D. High speed image techniques for construction safety net monitoring in outdoor conditions. Conferences on optics, photonics and digital technologies for multimedia applications. SPIE. Brussels (Belgium), April 2012.

[11] González, A., Ríos, F. Effects of Positive Accelerations on the Human Organism. Aerospatiale and Environmental Medicine 2002, Vol. 3 (5): 222-231.

[12] Sulowski, Andrew C. How good is the $8 \mathrm{kN}$ Maximum Arrest Force limit in industrial Fall Arrest System? Seattle 2006. 